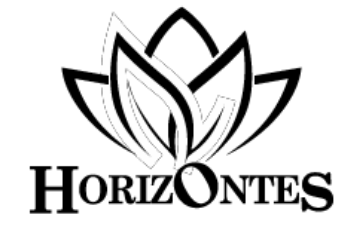

www.revistahorizontes.org

\title{
Rincón de lectura, estrategia en el desarrollo del lenguaje
}

\author{
Reading corner, language development strategy
}

Canto de leitura, estratégia no desenvolvimento da linguagem

\author{
Vicenta Ripalda'-2 \\ jubikaripalda@hotmail.com \\ Código ORCID: 0000-0002-4387-4256
}

\author{
Jessica Macías ${ }^{2}$ \\ maciasjessica29@hotmail.com \\ Código ORCID: 0000-0003-0379-6246
}

\author{
Marlene Sánchez Mata ${ }^{2}$ \\ marlenemata2000@hotmail.com \\ Código ORCID: 0000-0003-3241-5588 \\ Unidad Educativa Simón Bolívar, Ecuador1 \\ Universidad Estatal Milagro, Ecuador ${ }^{2}$
}

Recibido diciembre 2019 | Revisado enero 2020 | Publicado 01 de abril 2020

\section{RESUMEN}

La utilización del rincón de lectura, permite a los niños desarrollar el lenguaje por medio de un aprendizaje significativo, donde se utilice varias actividades que motive a los niños a leer. La investigación realizada a 102 docentes de educación inicial y primero de básica de Zonal 5 Ecuador, se evidenció que no están aplicando varias estrategias en este ambiente de aprendizaje, solo realizan narración de cuentos, cuando hay varias actividades que se pueden hacer como: intercambio de lectores, apadrinamientos, proyectos de elaboración de textos artesanales, que motivaran a los niños a interesarse por la lectura y la creatividad. Es necesario que los docentes también planifiquen para el uso de la biblioteca de aula, haciendo un itinerario donde se evidenciará el trabajo por parcial de cada una de las actividades que pueden realizar con su grupo de estudiantes.

Palabras clave: Rincón de lectura; estrategia; educador infantil

\section{ABSTRACT}

Using the reading corner, allows children to develop language through meaningful learning, using a variety of activities that motivate children to read. The research carried out on 102 primary and elementary teachers of Zonal 5 Ecuador, showed that they are not applying several strategies in this learning environment, they only perform storytelling, when there are several activities that can be done as: exchange of readers, sponsorship, craft projects, which motivate children to become interested in reading and creativity. It is necessary that the teachers also plan for the use of the classroom library, making an itinerary where the work will be evidenced by partial of each of the activities that they can carry out with their group of students.

Key words: Reading corner; strategy; Child educator 


\section{RESUMO}

O uso do canto da leitura permite que as crianças desenvolvam a linguagem por meio de aprendizado significativo, onde são usadas várias atividades que motivam as crianças a ler. A pesquisa realizada com 102 professores do ensino fundamental e médio da Zonal 5 Equador, mostrou que eles não estão aplicando várias estratégias nesse ambiente de aprendizagem, apenas realizam narrativas quando existem várias atividades que podem ser realizadas, tais como: intercâmbio leitores, patrocínios, projetos de artesanato, que motivarão as crianças a se interessarem pela leitura e criatividade. É necessário que os professores também planejem o uso da biblioteca da sala de aula, fazendo um itinerário onde será evidenciado o trabalho parcial de cada uma das atividades que eles podem realizar com o grupo de alunos.

Palavras-chave: canto de leitura; estratégia; Educador infantil

\section{INTRODUCCIÓN}

La práctica de la lectura es muy deficiente en los estudiantes de los diferentes niveles escolares, esto se va evidenciando cuando ellos no pueden ser capaces de comprender, interpretar, analizar, reflexionar $\mathrm{y}$ argumentar sobre los textos que son narrados por sus docentes. En los primeros años de educación escolar, el educador debe aplicar estrategias innovadoras en las bibliotecas de aula o rincones de lectura para que los niños y niñas se motiven en leer los diferentes textos que encuentran en el aula. En Latinoamérica, la OEI publicó que los países con mayor hábito de lectura son, Argentina con el 55\% y Chile el 51\%. En el año 2013, el INEC realizó la encuesta sobre el hábito de lectura a 5 ciudades del Ecuador, donde expresaron que el " $27 \%$ de las personas entrevistadas declaró no tener hábito de leer. De ellas, 56,8\% dijo que no le interesaba la lectura. Entre quienes dijeron leer libros, apenas $0.3 \%$ dijo hacerlo en una biblioteca" (Torres, 2014).
En las instituciones educativas en los primeros grados de Educación Básica, los docentes tienen un espacio destinado para el rincón de lectura o también llamado biblioteca de aula, donde ellos deben animar a los niños a leer y no lo hacen, pero muchos de ellos no conocen estrategias para animar la lectura en estos rincones por falta de capacitación. El objetivo de la investigación es el de proponer estrategias significativas a los educadores infantiles, que permitan a los niños interesarse por la lectura y a la vez involucrar a sus familiares en este hábito, donde podrán compartir aventuras interesantes que ayudará al niño y niña en el desarrollo del lenguaje.

Para (Castedo y Molinari, 2009) “Enseñar a leer supone desarrollar en el aula diferentes tipos de situaciones donde los niños tienen oportunidades para resolver problemas que les permita avanzar como lectores", los docentes en los primeros años de escolaridad deben promover situaciones que permita a los niños interactuar con los textos, ayuda a que ellos puedan disfrutar del momento de la lectura donde se desarrolla la imaginación y la creatividad de cada uno de ellos.

En la investigación realizada a docentes de educación infantil de la Zona 5 - Ecuador sobre estrategias que utiliza en los rincones o ambientes de lectura, se ha podido detectar que la mayoría realizan solo la narración de cuentos tradicionales, preguntas y respuestas, los niños no se motivan en la búsqueda de nuevos textos para leer; es necesario que los rincones o ambientes de aprendizaje de lectura sea un lugar interesante, donde tengan la oportunidad de escoger textos por autores, personajes, géneros literarios y así permitirá a los pequeños lectores desarrollar el lenguaje; (Colmer, 2001) expresa que se debe hablar sobre lo leído porque se aprende más y habrá mayor oportunidad para que lo hagan todos los niños y niñas. Se debe 
concienciar a los docentes que en el rincón de lectura

...los niños disfrutan que los adultos les muestren los libros y les ayuden a interpretar las imágenes y el texto, mientras manipulan, describen $y$ dialogan. Los niños desarrollan el lenguaje y aprenden a gozar de la lectura entendiéndola como una actividad interesante y placentera. Los adultos deben crear un vínculo de afecto con los libros (MinEduc., 2015).

Es necesario preguntarse entonces $¿$ Por qué el docente tiene que innovar estrategias para la práctica de la lectura? ¿En qué medida las estrategias que se aplica en los rincones de lectura contribuyen en el desarrollo de las habilidades del lenguaje verbal y no verbal en los niños y niñas de educación inicial? ¿Por qué es necesario fomentar en los niños y niñas el hábito por la lectura? ¿Cuáles serían las estrategias que pueden aplicar los docentes para mejorar el desarrollo del lenguaje a través de la práctica de la lectura? Actualmente en las instituciones educativas de la Zona 5, no están utilizando diversas estrategias para el uso de rincones de lectura, solo se han quedado en leer cuentos tradicionales y no buscar nuevas estrategias que motiven al estudiante a tener interés por leer. Según (Andes, 2014) "En las escuelas públicas hay un índice de lectura muy bajo debido a que no existen bibliotecas escolares y hay un déficit de bibliotecas públicas a nivel nacional".

En las instituciones educativas encuestadas, los docentes infantiles aplican solo dos estrategias como es: la lectura de cuentos en pictogramas y narración de textos, pero hace falta una planificación en relación a las actividades que se realizará en este ambiente de aprendizaje; de allí la importancia y necesidad de que los educadores se capaciten sobre estrategias en el uso del rincón de lectura. Para mejorar el desarrollo del lenguaje, existen diversas estrategias que pueden ser aplicar en los rincones, como son: intercambio de docente en la lectura, itinerarios, proyectos, circulación de bolsa viajeras, préstamos de libros, ejemplar único, entre otros, con el fin de desarrollar en el niño y niña la creatividad, imaginación, interés y amor por la lectura.

\section{DESARROLLO}

\section{La biblioteca de aula o rincón de lectura}

La biblioteca de aula o rincones de lectura según (Holzwarth, 2008) "permite al niño ser parte de un grupo de lectores que lo va formando como partícipe de una comunidad en la que existen derechos y también responsabilidades". Ayuda a los niños y niñas compartir ideas, hacer reflexiones y análisis de lo que han leído, irán construyendo nuevos conocimientos con la orientación de los docentes. La importancia de aprender a leer utilizando los rincones de lectura favorece al niño y niña en el desarrollo del lenguaje. Al establecer un plan estratégico para el rincón de lectura, los docentes sabrán qué actividades realizaran en cada parcial y cómo se motivará al niño hacia el hábito lector. Cada período lectivo, los docentes deben reunirse por nivel y seleccionar los saberes que aplicaran sobre la lectura. Para (Petit, 2009) "la lectura es un arte que más que enseñarse se transmite en un cara a cara. Para que un niño se convierta en lector es importante la familiaridad física precoz con los libros".

La biblioteca del aula según (Castedo.M, M, Cuter, y Cinthia, 2015) "ofrece un contexto apropiado para que los niños escriban por sí 
mismos, con ayuda del maestro o a través de él"; es un espacio donde a más de acercarse a leer, contribuye en el desarrollo de las habilidades lectoras, la creatividad y el enriquecimiento del lenguaje. La importancia de tener un rincón de lectura o biblioteca de aula ayuda al interés lector de los chicos. Para (Bischoffshausen, 1994) Este espacio permite una interacción más horizontal entre alumnos y docentes y ayuda a desarrollar los proceso de autoestima positiva e identidades individual y colectiva.

\section{Organización del rincón de lectura}

Para (Bello y Holzwarth, 2008) "implica tareas que garanticen su buen funcionamiento, por ello, hay que realizar actividades preparatorias que permitan poner en marcha este instrumento en la sala y en el jardín, actividades posteriores que logren mantenerla viva y darle sentido". Es de gran importancia la organización del rincón de lectura en el cual se puede distribuir los materiales utilizando itinerario de forma periódica; es decir se pueden ubicar los textos en el rincón de lectura por tiempos establecidos. Por ejemplo, trabajar por parciales, en el primer parcial se puede realizar lecturas de cuentos por personajes o autor, en el segundo parcial realizar proyecto de creación de texto artesanal como elaborar cancioneros, poesías, trabalenguas, enciclopedia de animales domésticos y salvajes entre otros, esto permitirá a los niños y niñas tener la oportunidad de intercambiar ideas con sus compañeros sobre los textos leídos.

\section{Estrategias en el rincón de lectura}

El educador infantil debe estar capacitado en estrategias significativas $y$ tener conocimiento de los materiales que va a utilizar en el rincón de lectura para fortalecer la enseñanza aprendizaje de sus alumnos.
Actualmente en las instituciones educativas se utiliza el rincón de lectura solo para ubicar cuentos tradicionales (Caperucita roja, Cenicienta, Los tres cerditos...) y que en un momento dado se entrega a los niños para que vean las imágenes o a su vez su docente le narre el texto. La lectura es otra cosa, es un proceso activo de construcción de significados a partir de los estímulos textuales (Cerrillo y Yubero, 2003), por tal motivo el educador debe realizar varias actividades prácticas como: leer portadas, títulos, autores, personajes de cuentos, fábulas, poesías, trabalenguas, canciones entre otros. Los niños cuando están en la etapa inicial de lectura deben aprender a realizar análisis cualitativo, les permitirá encontrar con mayor facilidad el texto que su docente le pide, es decir la maestra utiliza materiales tomando en cuenta criterios de selección, además empiezan a establecer relaciones lógicas entre una imagen y la escritura, son capaces de interpretar textos escritos, es decir le asignan un significado. Las estrategias sugeridas para el docente infantil son: intercambio de docentes, fichaje de libros, círculo de lectores, bolsa viajera, registro de préstamo de libros, agendas de lectura, realización de proyectos, realización de libros artesanales, ejemplar único. Estas estrategias han sido utilizadas en Argentina obteniendo buenos resultados con los niños, es un país que tiene un $55 \%$ en el hábito de lectura debido que desde la educación inicial se motiva a los niños a incursionarse en leer.

En el rincón de lectura también se debe establecer normas para su mantenimiento. Hay que establecer normas claras y sencillas para mantener el orden, la limpieza y la responsabilidad con respecto al material y espacios que utilicen. Los pequeños siempre deben dejar el lugar ordenado y no estropear aquellos materiales que utilicen" (Miriam y Raquel, 2010) "Si se le enseña a los niños 
normas de cuidado, los textos tendrán mayor duración, además serán los encargados de difundir los textos a sus familiares para que en el hogar también pongan en práctica la lectura familiar cuando los niños llevan el texto de la escuela al hogar por medio de la realización de un préstamo de texto.

\section{Préstamos de libros}

Es una actividad que se realiza en el rincón de lectura en el cual se destina los días viernes para que los niños seleccionen qué texto van a llevar a su casa y el día lunes debe devolver el texto explicando a sus compañeros de qué se trató y para los niños de los otros grados deberá llevar el resumen de lo que ha leído e indicar qué le agradó del tema. El beneficio que brinda esta actividad según (León, 2009) es que

"Se implica a las familias en el
proceso educativo y, sobre todo,
en lo relacionado con el libro,
pues leer al niño es de suma
importancia. - Fomenta la
responsabilidad del alumno, pues
el niño tiene que acordarse de
devolverlo y cuidarlo".

La familia es la primera alfabetizadora de sus hijos, si los padres desde temprana edad dedicaran a sus hijos tiempo en la lectura, ellos empezarán a tener interés por que le lean cada día más y al ingresar a la escuela cuando su docente empiece a leer textos, reconocerán de forma inmediata de qué se trata, cuáles son los personajes del cuento, cómo es el inicio y el drama, podrán con mayor facilidad realizar preguntas a su docente. La familia es la principal promotora en la formación de sus hijos como lectores. (Alliende, 1983). Por tanto, es indispensable que la familia se involucre con sus hijos en el hábito de la lectura, así ellos podrán apropiarse de esos escritos.

\section{Registro de libros prestados}

Consiste en realizar una ficha de cada estudiante en el cual irá registrado los nombres de libros que ha ido llevando a casa y saber cuántos textos a leídos por parcial, esto permite realizar estadísticas de los estudiantes que están leyendo los diferentes textos. "La biblioteca del aula ofrece un contexto apropiado para que los niños escriban -por sí mismos, con ayuda del maestro o a través de él- con el propósito de registrar su nombre en la ficha de préstamos si piden un libro para llevar a casa" (Castedo, Torres, Cuter, y Kuperman, 2015).

\section{Agenda de lectura}

Agendar los libros, es un recurso que favorece a los niños en la lectura donde van a ir identificando títulos, autores, editora. Se realiza una actividad donde los niños puedan elaborar y decorar su agenda.

También (Castedo, y Molinari, 2009) plantean que:

\begin{abstract}
"El docente escribe un listado de títulos a leer y su distribución en el tiempo (lecturas de la semana o del mes). Lo hace en un afiche y con el tipo de letra más conocido por los alumnos. Antes de leer la obra anuncia el título y solicita que lo encuentren en la agenda para marcarlo".
\end{abstract}

\section{Intercambio de lectores para la lectura de cuentos}

Es una técnica que permite a los docentes de educación infantil cambiar de aulas bajo una planificación con sus compañeros para leer los cuentos a otros niños en un horario determinado. El uso de los cuentos son recursos imprescindibles que ayuda la imaginación y creatividad de los niños además según (León, 2009) “Favorece el 
desarrollo afectivo, pues el niño y la niña, a través del cuento, podrá encontrar significado a los valores humanos y es un elemento canalizador de sus angustias y temores".

\section{Proyecto producción de textos}

Permite a los niños a ser investigativos donde realizarán proyectos como por ejemplo elaborar enciclopedia que ayudará a buscar las características principales de: seres humanos, animales, plantas, sabrán de dónde provienen, cuál es su alimentación, su hábitat, entre otros. Esta actividad favorece para la creatividad, reflexión y análisis de lo que está realizando a través del trabajo colaborativo con sus compañeros porque comparten ideas, inquietudes y soluciones para la realización de la actividad.

Para Cañabate, Espinosa, Alvarez, y Irigarat, (2011) plantea que:

Las producciones de niñas y niños deben tener un lugar en la biblioteca de aula, ya que, entre otras cosas, es un modo de reconocimiento al esfuerzo que hacen y a la validez de cada una de las etapas evolutivas por las que van pasando.

\section{Selección de materiales bibliográficos por parcial}

En la planificación que se debe realizar para la biblioteca de aula o rincón de lectura, se establece un itinerario en el cual se especifica qué textos van a trabajar los niños por parcial, además se puede clasificar por autores, personajes o géneros literarios, por ejemplo, si selecciona por personajes, se buscará al personaje y los diversos textos que se relacionen a éste. "El material de la biblioteca se renueva periódicamente para sostener el interés, ampliar y profundizar el horizonte lector de los niños" (Paione). La actividad, permite a los niños realizar análisis de un cuento con otro sobre el mismo personaje, sacarán sus propias conclusiones y ayuda a los chicos en la creatividad de formar un nuevo texto.

\section{Padrinos lectores}

Es una actividad donde se invita participar a estudiantes de Básica Superior y Bachillerato a ser padrinos lectores, cada uno de ellos tendrá ahijados de inicial o primero de básico. El docente por medio de una planificación establece que en un parcial del quimestre se realizará la estrategia e indicando hora y día para que se realice el encuentro entre padrino/ madrina con sus ahijados. "Es un aprendizaje cooperativo, en el que el más pequeño se siente acompañado y el más grande asienta recuerdos como primer lector, compartiendo motivaciones, gustos y experiencias"(García, 2015)

Mejora las relaciones interpersonales entre los compañeros, tienen mayor interés en buscar textos para narrar a los más pequeños, desarrolla la habilidad lectora $\mathrm{y}$ escucha activa. Para que sea formal, se realiza un contrato de apadrinamiento donde el padrino se compromete a buscar los textos para la narración y los ahijados tendrán el compromiso de escucharlo con mucha atención para luego contestar las preguntas que realizará su padrino.

\section{Ejemplar único}

Al realizar esta actividad con los niños, les permite tener mayor contacto con el texto, donde ellos se apropian del contenido y empiezan a comentar sobre las imágenes, deducen qué está sucediendo en cada escena y pueden realizar escritos con la ayuda de su docente utilizando sus propios códigos. Actualmente el primer año de educación básica, el Ministerio de Educación ha enviado cuatro ejemplares de cuentos donde el o la 
docente debe planificar en cuantas semanas y horas clases va a trabajar cada texto. "Todos los niños con el mismo libro en sus manos. En la formación de lectores de literatura, el maestro lee al menos dos veces el cuento de uno de los títulos que tiene ejemplares todos los niños Planifica diversas situaciones de lectura de los niños por sí mismos y también algunas escrituras." (Kuperman y Castedo, 2015).

\section{El educador infantil como promotor en la biblioteca de aula para el desarrollo de la lectura}

El docente tiene que ser innovador en su aula, más aún incentivar a los niños al hábito de la lectura a través de diferentes estrategias que utilice para la biblioteca de aula, debe poseer varias características como: ser positivo, respetuoso de las opiniones de los demás, ser crítico, reflexivo, creativo, comprensivo y dinámico. Lo que permitirá desarrollar en sus chicos: responsabilidad, normas, afecto, cuidado, amor a la lectura, mejorar su léxico y expresarse sin miedo ante los demás. "El promotor de lectura es aquella persona interesada en transmitir activamente el gusto de leer. Para el efecto, le nace buscar, crear, preparar y ejecutar acciones a corto, mediano y largo plazo." (Mantilla y Jhonny, 2016).
Los niños requieren un intermediario, un mediador que facilite sus primeros encuentros con los libros, que les ayude a descubrir el significado, la emoción y el gozo que encierran, que mantenga su interés en la lectura hasta que llegue a formar parte indispensable de su vida cotidiana. (Sainz, 2005)

\section{METODOLOGÍA}

El presente estudio fue una revisión documental donde se analizaron de forma sistemática documentos usando metabuscadores como google scholar, scielo, Eric, redalyc, entre otros, usando como indicadores estrategias para la lectura, rincón de la lectura, bibliotecas dentro del aula, importancia de la lectura, entre otras, también se realizó un trabajo de campo para conocer las realidades de las docentes de educación infantil de algunos establecimientos educativos de la Zona 5 del distrito en el cantón Milagros, Ecuador a fin de constatar si las misma están aplicando estrategias innovadoras en los rincones de lectura para mejorar el desarrollo del lenguaje propuesto por varios de los autores que se citan en este artículo. Los datos se obtuvieron de una muestra de 102 docentes, también es una revisión documental. (Ver tabla 1). 
Tabla 1. Encuesta a docentes de Zona 5

\begin{tabular}{|c|c|c|}
\hline UNIDAD EDUCATIVA & Ciudad & $\mathbf{N}^{\circ}$ Docentes \\
\hline $\begin{array}{c}\text { Unidad Educativa Simón } \\
\text { Bolívar }\end{array}$ & Milagro & 12 \\
\hline Escuela María Luisa de Viteri & Naranjito & 6 \\
\hline $\begin{array}{l}\text { Escuela de Educación Básica } \\
\text { Mariscal Sucre }\end{array}$ & Mariscal Sucre & 4 \\
\hline $\begin{array}{c}\text { Unidad Educativa Carlos } \\
\text { Moreno Arias }\end{array}$ & Milagro & 4 \\
\hline $\begin{array}{l}\text { Unidad Educativa Eduardo } \\
\text { Kingman }\end{array}$ & Milagro & 6 \\
\hline $\begin{array}{c}\text { Escuela de Educación Básica } \\
\text { Mariano Unda }\end{array}$ & Naranjal & 6 \\
\hline $\begin{array}{c}\text { Escuela de Educación Básica } \\
\text { Roberto Espíndola }\end{array}$ & Milagro & 4 \\
\hline $\begin{array}{l}\text { Unidad Educativa Victoria } \\
\text { Macías de Acuña }\end{array}$ & Milagro & 4 \\
\hline Escuela Eloy Alfaro & Parroquia Virgen de Fátima & 4 \\
\hline Escuela 24 de Mayo & Milagro & 4 \\
\hline Escuela Ernesto Seminario & Milagro & 6 \\
\hline Escuela Modesto Chávez & Milagro & 4 \\
\hline $\begin{array}{c}\text { Escuela particular Luis } \\
\text { Vernaza }\end{array}$ & Marcelino Maridueña & 4 \\
\hline $\begin{array}{c}\text { Centro de Educación Inicial } \\
\text { Yasuní }\end{array}$ & Naranjito & 4 \\
\hline Unidad Educativa Milagro & Milagro & 4 \\
\hline Escuela Padre Daniel Diez & Simón Bolívar & 6 \\
\hline Unidad Educativa Ferroviaria & Bucay & 4 \\
\hline $\begin{array}{c}\text { Escuela José María Velasco } \\
\text { Ibarra }\end{array}$ & Balao & 6 \\
\hline Escuela León Febres Cordero & Milagro & 4 \\
\hline Escuela Inés María Balda & Daule & 6 \\
\hline TOTAL & & 102 \\
\hline
\end{tabular}

\section{RESULTADOS Y DISCUSIÓN}

Los educadores infantiles no están utilizando estrategias para la biblioteca de aula o rincón de lectura, esto desmotiva a los estudiantes a la búsqueda de información y construcción de proyectos que ayudarán al desarrollo del lenguaje y la escucha activa. El 82\% de los educadores expresan que sí tienen un espacio físico para el arreglo del rincón de lectura, apenas el 12\% no lo tiene, (Gráfico 1). Al existir un rincón de lectura, el docente tiene que tener una planificación donde esté organizada las diferentes actividades que van a realizar durante el período lectivo, lo cual no se evidencia un plan estratégico en el uso del rincón de lectura 


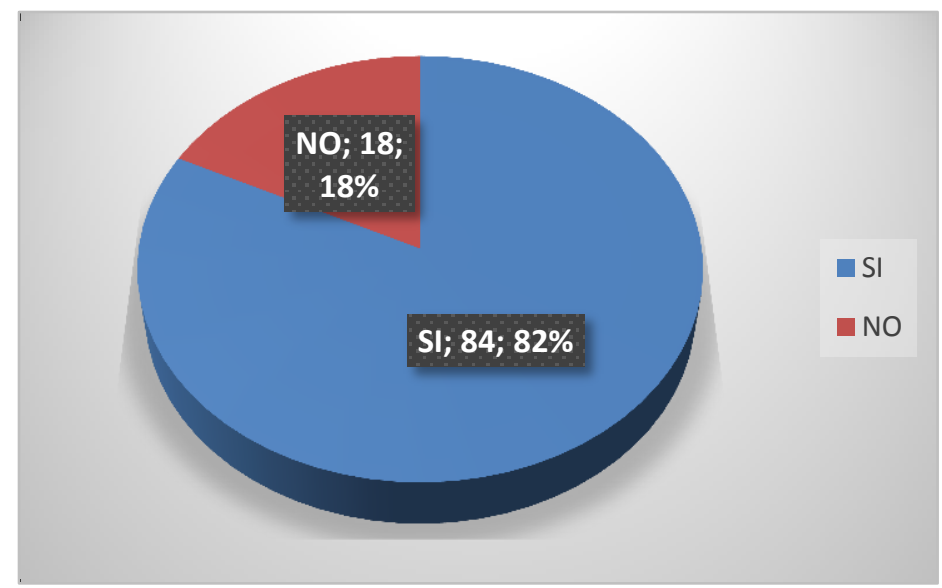

Gráfico 1. En el aula de clases existe un espacio físico para el rincón de lectura

El uso del rincón de lectura, los docentes lo utilizan con los niños apenas el $35 \%$ los 5 días a la semana, el $23 \% 4$ días, el $27 \%$ solo 3 días y el $15 \%$ utilizan el rincón de lectura 2 días a la semana, (Gráfico 2). El Ministerio de Educación expresa que el uso de las Bibliotecas de aula deben ser los cinco días de la semana con el fin de desarrollar el lenguaje de los niños. En la actualidad también se ha establecido que "se puede utilizar el tiempo del currículo destinado a los 30 minutos de lectura para hacer lecturas previas y preparatorias para las actividades de la Fiesta de la Lectura" (MINUDEC, 2016)

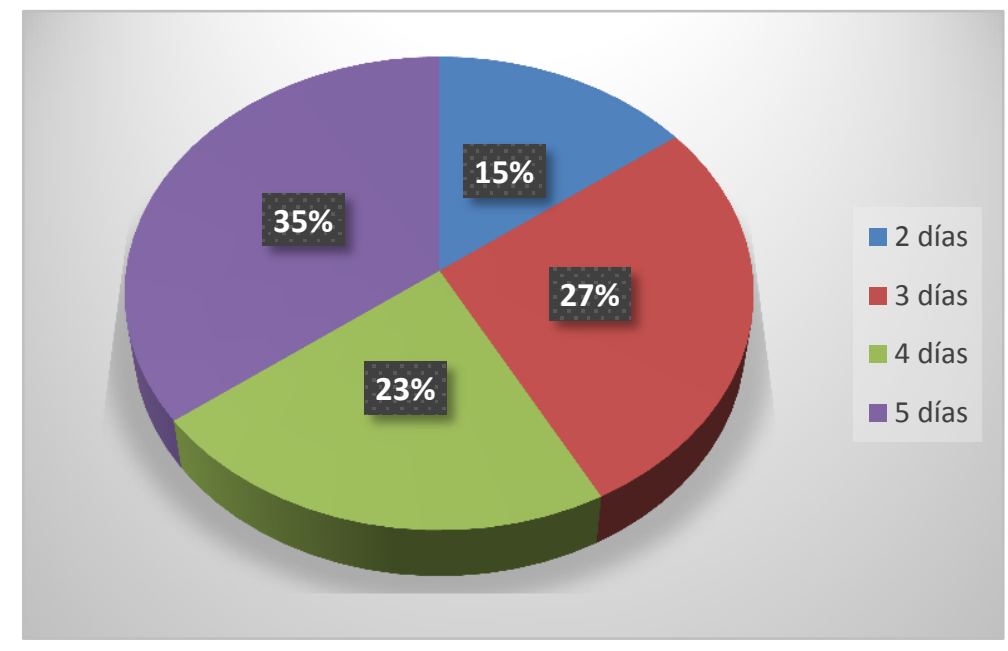

Gráfico 2. Cuántos días de la semana los estudiantes practican la lectura en la biblioteca de aula.

El tiempo que se utiliza el rincón de lectura, se refleja un $39 \%$ es de 20 minutos, el $38 \%$ utilizan 30 minutos, $13 \%$ es de 40 minutos y por último el $10 \%$ de los docentes tienen un tiempo en el rincón de lectura de 1 hora (Gráfico 3). El uso de los rincones de lectura en los primeros años básicos, es alrededor de 20 minutos, es el tiempo en que los niños prestan atención en la actividad que se está realizando, están predispuestos a escuchar la narración y a contestar preguntas que realiza su docente, este momento debe ser de interés, donde llame la atención al niño hacia el hábito por la lectura. 


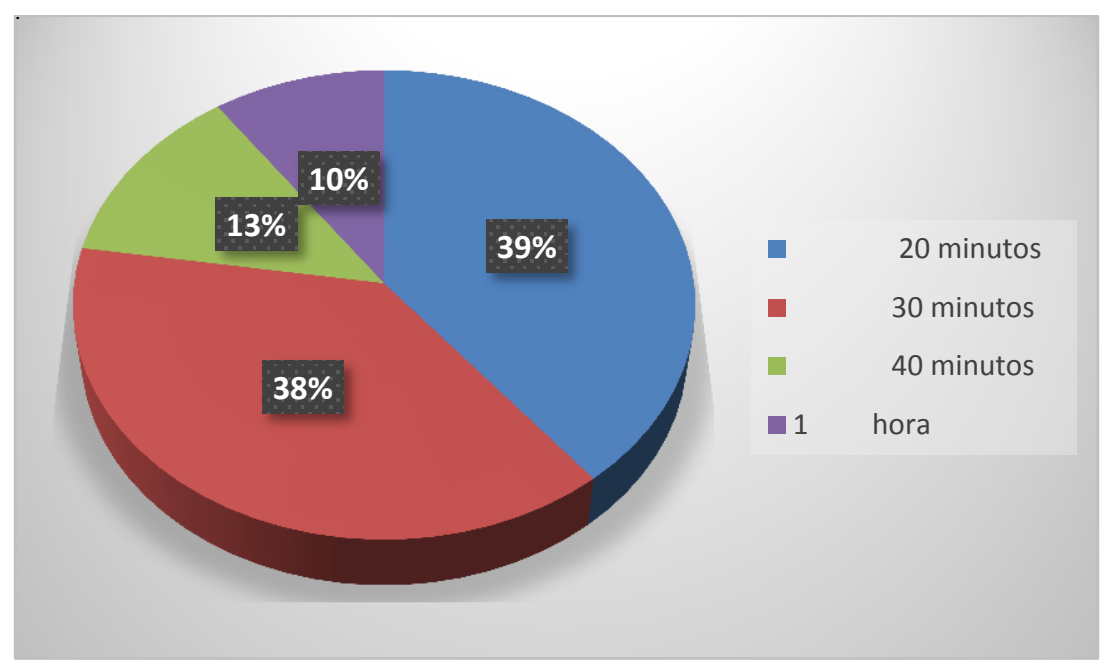

Gráfico 3. Tiempo designado para el rincón de lectura

En esta encuesta se refleja que los educadores infantiles solo están utilizando una o dos estrategias en los rincones de lectura, el 57\% de ellos aplican narraciones de textos, el $27 \%$ lectura de cuentos en pictogramas, el $8 \%$ realizan intercambio de lectores y un $8 \%$ circulación de bolsa viajera. Al realizar la estadística también se evidenció que un 28\% utilizan dos estrategias (Gráfico 4). Se necesita que los educadores estén orientados sobre las diversas actividades que se pueden realizar en los rincones de lectura a través de una buena organización y planificación en conjunto con las autoridades para mejorar el aprendizaje de los niños y a su vez que ellos tengan la curiosidad de conocer varios géneros literarios y realizar proyectos como la creación de textos artesanales donde desarrollan habilidades y destrezas que fortalecerán el nivel cognitivo de los niños. "Utilizar libros apropiados para la edad y rotarlos periódicamente.
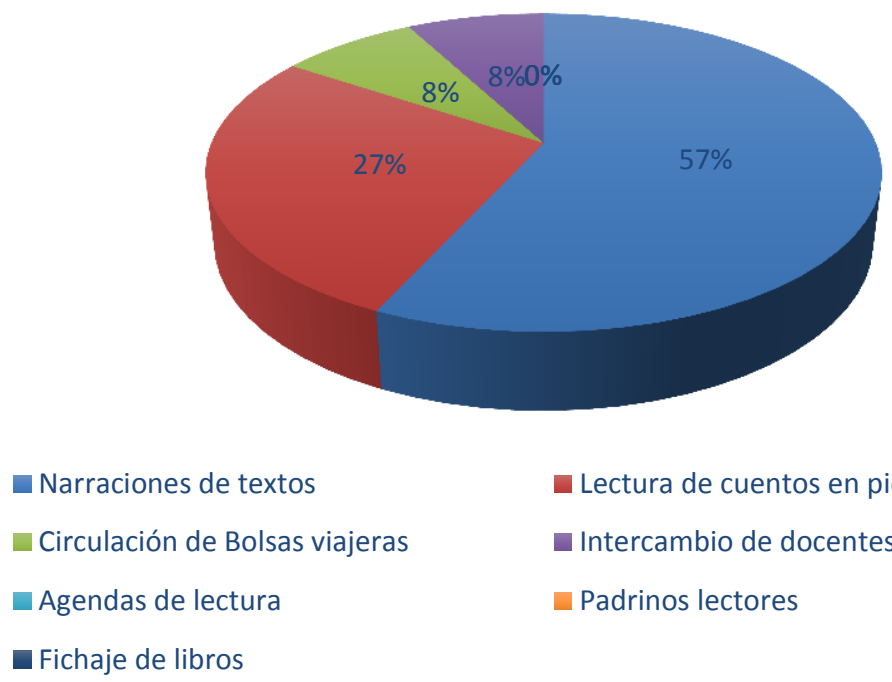

- Lectura de cuentos en pictogramas

- Intercambio de docentes para la lectura Padrinos lectores

Gráfico 4. Estrategias para la práctica de lectura en las bibliotecas de aula o rincones de lectura. 
En la organización de los textos en el rincón de lectura, se videncia que no existe un itinerario para la ubicación de los textos. Al preguntar a los docentes de cómo han distribuidos los textos en la Biblioteca de aula, se reflejó que el $64 \%$ ubican los textos sin ninguna clasificación; es decir no están clasificados por personajes: como princesas, lobos o por autores; el 19\% indicaron que si clasifican los textos por personajes el 14\% lo realizan por género literario y apenas un 3\% seleccionan los textos por autor (Gráfico 5). Es importante que exista una planificación para la organización del rincón de lectura donde exista una variedad de textos. Si los niños ven los mismos libros durante todo el año, se aburren pronto y ya no quieren leer. (MINEDUC, 2014).

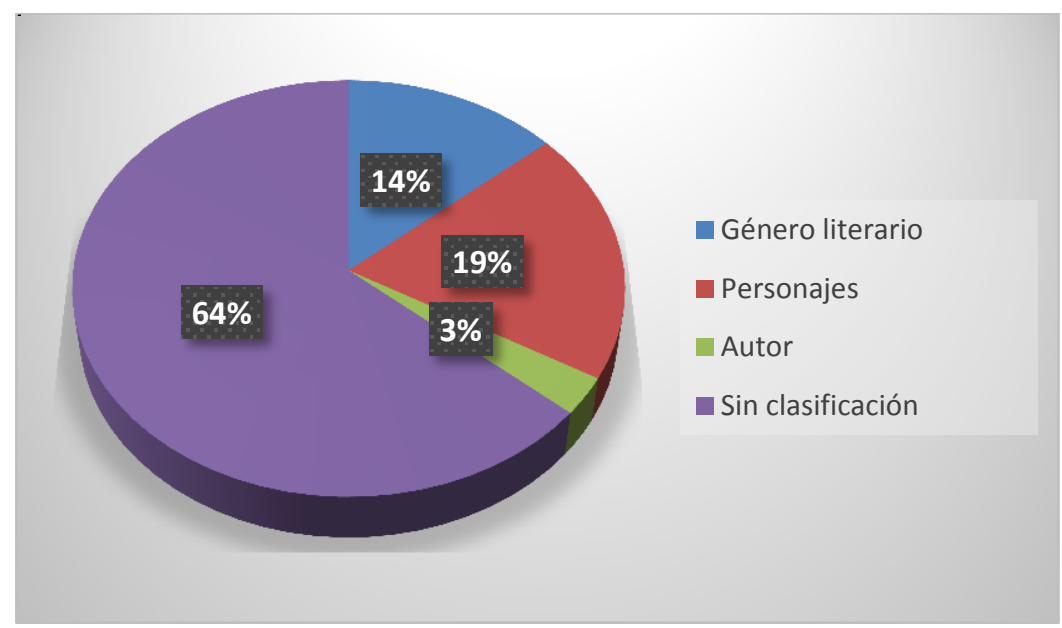

Gráfico 5. Clasificación de los textos en el rincón de lectura.

En la encuesta se evidenció que la mayor parte de los docentes ubican los textos en los rincones de lectura sin ninguna clasificación, debido que no hay una planificación para la utilización de textos en un tiempo determinado, el $64 \%$ expresa que no clasifican los textos, solo ponen en el rincón de lectura los que tienen y no se realiza ninguna otra actividad, el 19\% indican que seleccionan los libros por personajes, el 14\% lo hacen por género literario y apenas un 3\% lo hacen por autor.

\section{CONCLUSIONES}

La biblioteca de aula, es un espacio donde los niños tienen la oportunidad de desarrollar su lenguaje $y$ tener un aprendizaje significativo. El docente puede utilizar varias estrategias que le permitirá fomentar el hábito lector en los niños. Para
Bischoffshausen, las prácticas de lectura en la biblioteca de aula es una actividad clave que permite a los niños a ser creativos y críticos de los textos que les son narrados.

En este ambiente de aprendizaje, se debe realizar una planificación donde especificar qué actividades va a realizar como es: préstamos de libros, registros de textos, agenda de lectura, padrinos lectores, intercambio de lectores para la lectura de cuentos, actividades con ejemplares únicos, proyectos producción de textos. Por tanto, es indispensable que los docentes se reúnan por niveles antes de iniciar un período lectivo con el fin de aportar con sus experiencias, ideas y creatividades para ponerse de acuerdo con sus compañeros qué saberes van a realizar en cada parcial; así los niños no se van a sentir obligados a leer, sino más bien estarán interesados por las historias que les narren 
sus docentes, dando respuestas a sus inquietudes, los proyectos de elaboración de textos artesanales donde ellos pondrán desarrollar la creatividad por medio del trabajo colaborativo con sus compañeros. Si se pone en práctica las estrategias sugeridas, se está motivando a los niños desde temprana edad hacia el amor por la lectura, esto brinda beneficios en el desarrollo cognitivo de cada uno de ellos.

\section{REFERENCIAS}

Alliende, F. (1983). Los padres y el comportamiento lector de sus hijos. Parapara

Andes, A. (23 de marzo de 2014). Día Mundial del Libro: Ecuador mantiene un bajo hábito de lectura. Obtenido de http://www.andes.info.ec/es/noticias/di a-mundial-libro-ecuador-mantiene-bajohabito-lectura.html

Bello, A., y Holzwarth, M. (2008). La lectura en el nivel inicial. Buenos Aires

Bischoffshausen, G. (1994). La biblioteca de aula: un espacio educativo con proyección. Revista Tarea. Obtenido de http://tarea.org.pe/wpcontent/uploads/2015/08/Tarea_34_44_ Gustavo-von-Bischoffshausen.pdf

Cañabate, C., Espinosa, F., Alvarez, A., y Irigarat, M. (2011). Las bibliotecas escolares en el aprendizaje de la lectura, la escritura y la oralidad. Clasve XXI

Castedo, M., y Kuperman, C. (s.f.). "Semianrio Planificación". Especialización Docente de Nivel Superior Alfabetización para la Unidad Pedagógica

Castedo, M., y Molinari, C. (2009). La lectura y la alfabetización inicial. Buenos Aires, Argentina. Obtenido de http://www.waece.org/escuelaverano_le ctura.pdf

Castedo, M., Torres, M., Cuter, M., y Kuperman, C. (2015). Alfabetización en la Unidad pedagógica: Módulo 1 Biblioteca de aula. Argentina: Ministerio de Educación de la Nación.

Castedo.M, M, T., Cuter, M., y Cinthia, K. (2015). Biblioteca para el aula. Buenos Aires.
Cerrillo, P., y Yubero, S. (2003). La formación de mediadores para la promoción de la lectura. España: CEDLI

García, J. (2015). Motivar el hábito lector en $1^{\circ}$ de Educación Primaria. Barcelona

Holzwarth, A. B. (2008). En La lectura en el nivel inicial. Buenos Aires

Kuperman, C., y Castedo, M. (2015). Seminario de Posgrado: Planificar la enseñanza de la lectura y la escritura en la escuela. Buenos Aires: Ministerio de Educación Nación

León, S. (2009). El rincón de la biblioteca, imprescindible en Educación Infantil. Revista digital para profesionales de la enseñanza. Obtenido de https://www.feandalucia.ccoo.es/docuip df.aspx?d=4656ys=

Mantilla, L., y Jhonny:, L. (2016). El Promotor de Lectura, Técnicas de Dinámicas y TIC.

MINEDUC. (2014). Guía metodológica para la implementación del Currículo de Educación Inicial. Ecuador: Ministerio de Educación

MinEduc. (2015). Guía metodológica para la implementación del currículo de Educación Inicial. Ecuador. Obtenido de https://educacion.gob.ec/wpcontent/uploads/downloads/2015/05/G uia-Implentacion-del-curriculo.pdf

MINUDEC. (2016). lineamientos generales Fiesta de la Lectura. Ecuador

Miriam, y Raquel. (1 de mayo de 2010). La educación preescolar. Obtenido de http://mmmiriamraquel5blogspotcom.bl ogspot.com/

Molinari, C., y Castedo, M. (2008). La lectura en la alfabetización inicial. La Plata: Subsecretaría de Educación

Paione, A. (s.f.). Biblioteca de escuela, de aula y virtuales

Petit, M. (2009). El arte de la lectura en tiempos de crisis. Argentina: Clarín

Sainz, L. (2005). La importancia del mediador: Una experiencia en la formación de lectores. Revista de educación, 357-362

Torres, R. (2014). Ecuador lector. Obtenido de http://otraeducacion.blogspot.com/2014/12/ecuad or-lector.html 